\title{
TO WHAT EXTENT DOES YOUTUBE CONTENTS-BASED LANGUAGE LEARNING PROMOTE AN ENGLISH PROFICIENCY?
}

\author{
Dedi Aprianto \\ Universitas Bumigora \\ Mataram, Indonesia \\ Dediaprianto44@gmail.com
}

\begin{abstract}
The flourishing development of technological software could have been as the necessary reality. The everchanging technological learning media emergence as the description of digital disruption in educational contexts. Teaching English as a Foreign Language is regarded as a challenging activity, since language teaching is strongly expected to have a quality teaching strategies to improve English proficiency. YouTube is principally designed to increase both aspects of language competency, and personal aspects of EFL learners, such as learning motivation, critical thinking, and learning autonomy. YouTube represents the presence of the sifting educational paradigm from the traditional teaching or teacher centeredness to authentic or meaningful language learning, in which these would have been centralized on EFL learners' domain (student-centered learning). The constructive changing of language approaches are indicated by the use of web 2.0 software presenting varying types of webs-based language learning software, YouTube. It is properly regarded to have contributed to produce the authentic and meaningful learning sources. And also, this learning model could have been made as the supplementary materials, in purpose of incorporating the traditional face-to face class activities into language learning supported by e-media. All in all, Those YouTube-based language learning's advantages could contribute to build up independence of language learning. Therefore, the effectiveness of YouTube-based language learning potentially develop EFL learners' class participation; social engagement, critical thinking, better comprehension of the subject-matters, and learning autonomy.
\end{abstract}

\section{Keyword: YouTube, EFL Learning-Instruction, English Proficiency}

\section{INTRODUCTION}

The development of various types of language learning media in educational realm is the initiation to go into facing the industry 4.0 as well as deserving the digital disruption. Everything is ever-changing and those adjust the social demand along with the contextual development in EFL learning. The nature of curriculum design principally responds to the educational obstacles as to achieving the goals of national education. Teaching a language is considered as a challenging activity, hence English language teaching needs quality teaching models in favor of ensuring and even promoting EFL learners' English proficiency. Thereby the aim of English language teaching is to lead the learners to be proficient speakers, so English teachers need to construct the basic principle of English Language Teaching (ELT), in such as learning models, subject matter / materials, and learning approaches. One of the most important principles which must be paid attention is motivation as well as quality materials which will be engaging, interesting, and up to date materials. Prior to digital learning media, there is a great 
deal of types of printed English materials being used in classroom. Those would have not motivated EFL learners despite of the conventional ways. On the contrary, the presence of digital learning media utilized as tools, materials, methods, is considered as the elements ensuring EFL learners' interest and even accommodating their demands.

In this paper, a writer elaborates the importance of using Youtube, as one of the social media, serving a lot of websites which comprise of the plethora of online driven videos-based sources. Thus this social media is a moving, animated, and interactive learning media which can easily and flexibly be accessed by EFL learners as learning materials. A number of scholars have suggested the use of videobased learning media, in EFL learning contexts can contribute to lead a salient part of English curriculum (Ismaili, 2013). Thereby the initiative to accommodate video-based language learning-teaching would contextually be effective. This is simultaneously supported by the fact that the use of movie model can provide the exposure to the real language contexts, because language materials are used in the authentic settings and in the cultural ones in which the target language is being spoken (Ismail, 2013). In addition videolization-based materials can evoke learners' interest and positively trigger their motivation (Kusumarasdyati and Luo, 2004 in Ismail, 2013).

The use of visual texts formed in a video presentation would be so attractive, hence according to Ismail's research on the effectiveness of using movies in EFL context, that most of the students feel bored and unmotivated in reading texts, instead of the authentic sources of learning. Thus the novel paradigm must be made-up by using the presentation tools, videos or movies. The scholars, on media literacy suggested that as a good reader tends to a writing text would be the same with the good reader tends to a visual texts (Golden, 2001 in Ismail, 2013). This expresses that language learners predict, make connection, ask questions, and interpret when those find the written or visual texts. The use of many alternative learning tools such as, Youtube, Podcasts, Blogs, Wikis, and RSS is buzzly associated with the web 2.0 and represents the sifting educational paradigm in terms of using the technological sets of language learning means. The real implication is felt that the presence of sifting from the archetypical learning tools to usergenerated content or from learning bases on lecture notes, printed materials to power point-generated electric projector, websites, animation to learning bases on 
video-based (Duffy, 2008). Current learning process can be facilitated through online learning and even technological teaching by simply serving the contents to the EFL learners. What Duffy revealed on a new learning ecology where the web 2.0 technologies could be explored for collaborative learning and create language learning purposes, critical assessment, evaluation, and personalization of information. This is done as the development of web 2.0 technologies allowing the language teachers to engage the students in more interactive practices, collaborative content creation. Peer assessment and motivation of the students through the use of interactive learning media. Thus these can be fruitful for developing the authentic learning tasks, and promoting learning experience. Eventually the teacher must be able to conceptualize the possibilities in using the web 2.0/digital tools. This means that they must incorporate them into the students' experience (Duffy, 2008).

It is worthily thought that the role of youtube plays importantly in a great deal of human's aspects of life, such as searching plethora of information and business transaction, etc. it is truly notable to perceive that the use of youtubewebsites in educational realm especially in EFL learning process has a positive effects towards English learners. This new way of teaching-learning of English can share the multimodal text for in-class activities as the supplementary English materials which can be integrated into the traditional English lessons. Additionally the use of youtube can be considered as the supporting media which are able to the learners' understanding towards the subject matters, improve the EFL learners' performance, and upgrade the advancement of English understanding (Almurshi, 2016). Then the prominent role of youtube-websites (Watkins \& Wilkins, 2011) reveal online streaming video websites facilitate the authenticity of learning and even the autonomy of language learners. This also potentially contributes to produce the stimulating lessons. From the two primary advantages of youtube-based English learning, the exposure of authentic English production leads the EFL learners to more practice as social function. The promotion of learning style which allows the learner's own ways to learn English as their English as a Foreign Language (EFL), or this called as student-centered English learning.

The integration of technological properties or software is theoretically termed as English language learning immersion by incorporating technology usage to EFL learning. This can be carried 
out by allowing EFL learner to seemingly connect the abstract concept of a foreign language into their own actual experiences. Actually to enhance the degree of second language input must be carried out by the immersion teaching and technique to have a positive effect on language acquisition process, but then incorporating technology into classroom is to generate greater learners' autonomy and to instill language learning skills (Wang, 2005: Leung, 2004 in Watkins \& Wilkins, 2011).

The ways of the great youtube application in EFL learning process the teachers apply with a few new techniques to foster a speaking skill and a listening skill. This also can improve variety of EFL activities, namely conversation analysis leads heightened awareness of an effective conversation techniques and the problems of conversation transpiring which can be resolved. Movie trailer voiceovers are practiced through transcribing video on youtube under listening and speaking practices in order to help students correct or recognize their pronunciation. Famous movie scene reenactments technique is done by enacting parts of the movie being utilized as learning sources in EFL classroom. This way is properly suited for an intermediate to an advance for improving his / her quality of a spoken English physically as well as dramatically.
Vlogging as an online diary of video form which can be performed by any students having lowest English proficiency.

The second part of English skills that can be promoted by utilizing youtube application, as in reading and writing where these can be developed via videosbased learning by taking notes, summarizing, and leading the students on how to write based on the videos. The last is world Englishness where it is closelyrelated to what so-called as English as a lingua franca for modern English world. This concept is firstly coined by Kachru in 1980s. The ultimate aim of English teaching is to globalize an English speaking by communicating not only with native speakers, but also with non-native speakers. of this operational definition corresponding to world English concept, a writer reveals significant variety of classroom activities which can be performed through watching youtube movies, namely current events and media study which leading the EFL learners compare the news-clips about the events in cross-cultural nations. In the process of video studying within two or more different videos of each country, the students consider the contents of each video. The second way, cultural entertainment study is rather identical with the previous one involving the entertaining 
drama's clips demonstrating the different foreign culture towards foreign students, too (the EFL learners do not have such culture being studied) through English speaking activity. Eventually this activity this activity is considered as slightly more complicated way, so there are two phases followed by the assessment phase, namely providing the video drama to the students by discussing the contents of the video as well as making the comprehension question. That will be discussed to check up the students' understanding. The next phase is by reviewing the video containing cultural perspectives then making the transcript of the video. Furthermore process of doing this activity that the students may select their own video or the list of videos which are acceptable to use English countries in order to be understood than non-English countries as video learning sources (Watkins \& Wilkins, 2011).

\section{YouTube-Based English Learning Sources}

Entering the internet disruption era and as the great appreciation towards the use of technology's advancement allows EFL learners tend merely to digital-based language learning. The techno-based language learning paradigm is so-called as e-learning. It is properly considered as an interactive tool supporting to develop language skills and to activate an independent learning. Fostering EFL skills by learning and even activating the independency of language learning must have been discussed as the paramount issues on ELT research, as the most limited opportunity of the traditional classroom contact cannot help the learners develop their English skills (Soliman, 2014). He additionally suggests the two main components of the use of e-learning, namely as learning activities as well as learning sources. He used e-learning Moodle as an alternative tool in EFL learning. Moreover, e-learning includes assignment, chat, choice, database, external tool, Forum, Glossary, Quiz, Wiki, Workshop, Hotspot, Lesson and SCORM Package. Thereby the use of elearning can be performed as the supplementary materials for face to face class activities. The two main components of e-learning can be used facilitate and monitor EFL learners to develop their English skills as well as independence of language learning (Soliman, 2014). It is line with what Soliman reveals on the use of technology-based learning, Mohammadi et al., (2011) shows the advantages of elearning, namely positive learning engagement, learning autonomy by posing a teacher's role as a facilitator, convenient for EFL learners to access any time and 
any place, a corporative learning model, comprehensive learning, and the use of elearning as the automatic trigger of learner's motivation.

YouTube and even video-based materials are considered as an effective method in ELT in both inside classroom, and outside classroom. The use of this method seemingly is more original and authentic way in EFL learning process. Moreover, this authentic material can properly be incorporated into the traditional classroom environment that leads ELT to become more interestingly and meaningfully (Bajrami \& Ismaili, 2016). The usage of this YouTube-based is designed to authenticate the contents of learning, as they are produced in original and authentic programs, such as English films, American movies, English songs, etc. Video-based language contents can be carried out through variety of instructional classroom settings, as in presenting contents, initiating discussion, illustrating certain topic and contents, self-study and evaluation situation should include the four integrated skills. Bajrami and Ismaili (2016) mention video-based materials can contribute to EFL learners' opportunity to learn about the target language's culture and mentality by practicing them into varying communicative contexts.

\subsection{The Authenticity of English Materials}

The use of YouTube is an ever flourishing medium in EFL learning and designing EFL resources which lead learners as well as teachers to offer an enormous possibilities to practice and develop their English skills. YouTube, which is visited one billion internet users per-month and the second largest video search engine, is the largest video portal. This is localized in 56 countries across 61 languages with variety of videos supplied on all topics and interests. The enormous amounts of video sources on YouTube application let the teachers feel responsible to design, create and make an English material sources more meaningful and increasingly (Brunner, 2013).

In Sherman (2003) cited by Bajrami and Ismaili (2016) argues that the incorporation of authentic video materials into language classroom activities, in which she provides varied practical classroom engagement showing how to use video in transmitting the real world language and culture of language into classroom context along with an engaging and productive method. Thereby Bajrami and Ismaili believe that the use of YouTube software as a medium of a 
language learning possesses great potentials to offer the authenticity or to provide the authentic English inputs through life experience. Furthermore video materials-based can stimulate EFL learner's autonomy as well as productivity by acquiring a great of amount of cultural knowledge and emotional attitude on the learning materials. Therefore they can be autonomous in EFL learning process. The use of visual show on YouTube is EFL learning depicts that the authenticity of language learning which can develop language skills. According to Noerdin et al., (2014), movies and commercial video clips on YouTube have positive responses towards the users, in which they can decrease their own anxiety, share about the clips, and respond what the other comment on video clips. Thereby this is so potential to use, hence it indicates the positive impact showing the EFL learners communicate under friendly-collective situations as well as less pressed settings by providing more opportunities to engage in social participation. In favor of getting English demanded proficiency, Noerdin, et al., moreover, reveal the integration of technology in ESL classroom will bring the positive development on ELT process, in which the technological tools contribute to ESL teachers for designing much more stimulating lesson plans as well as effective lesson plans. Therefore welldesigned English courses can subsequently enhance learners' English proficiency, as technology-based learning become more relaxed and spontaneously.

The definition of 'authentic' is everything which a native speaker hears, reads or the usage can be categorized as authenticity, such as English TV programs, newspapers, poems, English songs, movies, and English YouTube broadcasts (Gower, 1995 in Konoplianyk, 2018). The authentic material is specifically designed for ESL learners. The authenticity of English material is properly considered as one of the techniques which can foster English proficiency for the professional communication skills. In addition, the authentic material in form of video contains the visual representation as the supplementary information to the content. Isupova (2016 in Konoplianyk, 2018) mentioned the use of the visual show can contribute best by allowing the learners to comprehend the content better for both factual information and linguistic intricacy. Thus authentic visual material can be as a support of a foreign language learning that can contribute to the meaning of English sound series and the development of ESL learners' phonemes and listening skills. In line with what Konoplianyk, Bajrami and Ismaili (2016), the video representation 
can provide the visual aid for listening skills. Theoretically the process of language learning consists of three key parts, namely language inputs (reading and listening), assimilation (internal processing and memorization), and language outputs (speaking, writing and translation). The three parts of language learning keys as the realization of English proficiency promotion which must be enhanced through the use of authentic video material, as that can stimulate the ESL learners' autonomy and even productivity. Eventually the ESL learners can acquire the cultural background information and emotional attitudes towards English materials. Then they can learn a language vividly by understanding the social pragmatics of language used (Bajrami \& Ismaili, 2016).

In relation with preparing the teaching plans and teaching practices, a teacher should keep goal in mind in order to achieve the teaching goal with video materials, namely facilitating the development of language skills especially listening and speaking, facilitating the video materials with visual aids for listening material, keeping focusing on the aural material, and using the authentic video materials can create more realistic language learning environment then can stimulate EFL learners' motivation, and can enhance the comprehensive linguistic competence (Bajrami \& Ismaili, 2016).

\subsection{YouTube Content as the Supplementary Materials}

The profound changing of technological advancement leads English teachers over the worlds to incorporate between e-learning with the classical learning environment. This is conducted in order to make an EFL learning effective and meaningful. It is undisputable that the advancement of e-media contribute more than what the traditional English teacher did. These can be employed through multimedia capabilities as well as interactive functions of the media. The use of e-media in various kinds of features, YouTube, can benefit to increase EFL learners' interest, can provide the authenticity of language, and can trigger the global awareness (Kelsen, 2009). The YouTube website can significantly be employed to become as a supplementary materials. Online video materials are regarded as e-media contributing for acquiring the multimodal texts occurring on the YouTube video materials (Almurshi, 2016). The reason why YouTube video is stuttered as the supplementary materials, as it can offer a 
great deal of materials along with multimodal texts must have provided incredible sources of information and varying kinds of information. The supplementary YouTube video materials can also be integrated to the traditional English learning approaches, since this online website is categorized as significant visual aids in EFL learning.

The mentioned English material is well-spread across the EFL learners, so they may access lots of English multimodal texts. The online YouTube website is primarily accessed, as that is indicated by a better facility to find out relevant, vivid, and authentic sources of English material. These can lead the EFL learners to improve their English performance. Eventually YouTube video material will both contribute EFL learners good comprehension as well as knowledge in a formal classroom, and make English learning environment more meaningful and much happier (Almurshi, 2016). YouTube video material is considered as a beneficial and interesting media to English as a Foreign Language learning, because Learners find experience of using YouTube in a learning environment. Thus the whole participants of classroom should involve in a creative and productive way to incorporate the YouTube website with a variety of classroom activities. Thereby this can be beneficial to provide a proper class environment as well as to foster learning outcome (Kelsen, 2009). It is thought that what Dodd et al.(2015) note is related to what Kelsen proposed on the use of YouTube websites as language sources that those kinds of material can contribute to stimulate EFL learners' motivation. Moreover, Dodd et al. added the presence of supplementary materials can improve the EFL learners' possibilities. More understanding towards the materials and the social participation. Thus, the supplementary materials can evoke learning environment more dynamically and interactively.

Fundamentally, the supplementary learning sources can be in various learning sources, such as flashcards, Power-Points (PPt), tables, posters, songs, dialogues, stories, and videos, etc. by using these varieties of the supplementary materials. According to Dodd et al. (2015), the use of supplementary learning sources that are based on the varying types and the numbers of the learning sources are dependent on the individuals or teachers in purpose of stimulating EFL learners' interest. In addition, to achieve the goals of language learning in classroom, English teachers must be triggered to facilitate the EFL learners' motivation. 


\section{The Effectiveness of YouTube} ensuring an English Proficiency

What is foresaid reveals the use of techno media-based learning can support EFL learners. Another benefit of the websites-based possesses an effective role of the multimodal text existing in YouTube sources. Moreover, Almurashi (2016) suggests the availability of YouTube's impact towards increasing EFL learners' deep understanding. Improving language learners' performance and upgrading their levels of English proficiency. YouTube is considered as supplementary materials which can be incorporated into the traditional English materials (mixed sources). In other words, websites-based learning can contribute to become an effective language model for facilitating learners' language anxiety and other barriers in understanding the contents of the subject matters. The use of webs-based teaching model is suggested by Whithaus and Neft (2006 in Almurshi, 2016), video materials-based can both provide learners the a lot of chances to utilize the video sources as means of learning, and produce interactivity amongst the EFL learners to support the social pedagogy in class engagement. The webs-based video materials are both well-regarded as beneficial media towards English teachers who are interested in technology for their teaching purposes, and an attractivelysocial medium contributing to a global education. The advancement of technological means serves the multiple ways to study a language inside or outside the classroom and lets the learners use online sources to support their language learning. The purposes of studying a language are to master its language skills. Thus hat is suggested by Jalaluddin (2016), using YouTube can be very useful to promote speaking, listening and pronunciation by allowing EFL learners to be aware of varieties of English used in over the world.

Worthily YouTube as the website which shares different kinds of sources or contents, such as video clips, streaming TV programs, music, video blogging, short original videos, and educational videos, etc. This is not only regarded as an entertaining media showing bulk of entertainment events, but also a large number of ELT videos. English Language Teaching (ELT) video sources could be made as beneficial means to study about different English dialects and even the varieties of English used around the world. Eventually Jalaluddin (2016) mentions that a great deal of the scientific researches on CALL (Computer-Assisted Language Learning) to teach an English has positive impacts towards English as a Foreign 
Language learners' English mastery. Furthermore, Brook (2011) reveals YouTube can facilitate language learning and teaching, increase confidence, provide authentic materials, and foster the social participation. And also, this can be utilized to produce the learners' autonomy by giving a large number of opportunities for independently learning.

According to Jalaluddin, he shows a large amount of activities which can be initiated to utilize YouTube web to teach not only speaking and listening, but also reading and writing, namely prediction allows the language learners to tell what the video content is. Vocabulary building is the process of watching video, in which the learners are asked to write down or to take note words and phrases which are relevant, interesting, and incomprehensible. Then they are asked to make a summary. In this phase, a teacher needs to discuss those points after having watched video by asking reason or opinion why they took note on the certain words. Next is describing main points, asking questions, and sharing opinions. The last step is carried out by grouping language learners, determining atopic which will be discussed and making active engagements. The other benefits of YouTube which are traced throughout several research findings, namely the emergence of critical thinking skills, learning autonomy, and learning interest. These will specifically be elaborated, as follows:

\subsection{Critical Thinking}

The advancement of technological application must have been well profusion and easily accessed. The emergence of massing videos on YouTube which can be made as authentic learning materials can develop the reflective thinking and even critical thinking that belong to EFL learners. It is thought that the selection of available videos on YouTube can be regarded as meaningful way language learning (Jonassen, 1996 in Bastos \& Ramos, 2009). Moreover, they cited in Felix (2002) and O'Dowd (2000), that both facilitating foreign language learners with the selected authentic materials which engaging them to communicate the real contexts, and fostering the development of understanding and communicative skills (speaking and writing). Intercultural competence is thought as a crucial role in an EFL learning.

In relation with the effectiveness of YouTube, Bastos and Ramos (2009) reveal the potentials of YouTube which is made as the effective pedagogical learning source lies on the way it is employed rather than it is as a technological device. Thus YouTube has a very important role which 
must be regarded that the goals of language learning must be adapted towards the contexts and characters of the language learners by determining on what is required to learn and to produce at the end of the lesson. So that is why, EFL learners are needed to select appropriate video sources. YouTube proves that the great advantages over the other language learning media, such as traditional textbooks, slides, overhead projector, and films, in which learners started to select the videos with critical eyes and to ask teacher to incorporate the video materials into classroom regular activities. Thereby this is concluded that the effective tool can help them obtain the objectives of language learning by engaging them to participate in the class. So, the effectiveness of using YouTube reveals that easy assimilation of vocabulary, active participation in arguing the distinct viewpoints, better understanding, clearer ideas, and meaningful contents. This medium can induce to contribute on EFL learner's critical thinking skills (Bastos \& Ramos, 2009).

The significant shift of language mastery is form the traditional contents of language curriculum as well as the traditional language learning paradigm to social meanings-based language learningteaching, in which the language courses focus on the drills and social practices. This transformation can potentially affects critical thinking skills (Kawamura \& Wu, 2015). Formally, today's curriculum should be designed to induce language learner and to support their thinking process. The design of educational curriculum involves the integration of various knowledge, such as ethics, moral values, and other characteristics that can increase the academic developments in the core curriculum. Thereby a such curriculum is to be applied through engaging the learners in the activities describing them that they must synthesize the materials served, discuss the materials collectively with their peers, and do a research to support their claims will contribute to the skills of higher order thinking (Kawamura \& Wu, 2015).

Critical thinking skills are seen as skills which are developed in a higher education. As Kawamura and $\mathrm{Wu}$ mentioned that a critical thinking ability is a composite which must accompany the outcome of higher education in the traditional concept. Furthermore it has a broad scope which can be employed in the studies in different fields. Thus critical thinking is educationally developed for educational purposes. Critical thinking ability tends to the general skills of reasoning; understanding information 
logically and critically (Davies, 2015 in Kawamura and $\mathrm{Wu}, 2015)$. The positive impact of video having a website to present language learning resource can significantly produce learning income leading to critical thinking skills through skill of argumentation, reorganizing, constructing the information, and decisionmaking. Thereby the use of selected YouTube materials based on the reality, subject-matters, and appropriateness of materials can contribute to EFL learners' language skills (listening and the other language skills).

Moreover, they can be used to foster learners' the understanding of topics comprehensively and generally, as those consist of visual audio impacts on language learning. Then those can be made use as a medium of language instruction for providing non-native English speaking learners the additional cues for supporting their own comprehension. Moreover, there three critical thinking skills found through the EFL learners' effective essays, namely the usage of conclusive statements towards the contents they learn on different sources, the use of convincing ideas about the topics learned, and making the reasonable judgment amongst the different information in the classroom (Kawamura $\& \mathrm{Wu}, 2015)$.
In relation with Kawamura and Wu's research on the emergence of critical thinking skills, June et al, (2014) suggests English material videos-based websites can contribute to enhance critical thinking skills. Moreover, they add that the use of YouTube are fun and attractive and it can lead learners' engagement and class participation. These are caused by learning a language visually as well as getting informational authentically. They can comprehend the materials learned better, so they participate actively and demonstrate a strong interest. Therefore YouTube's clips can be fruitful, interesting, motivating to many EFL learners (Kawamura \& Wu, 2015). The use is regarded as a language learning tool which can not only trigger psychological aspects of English learners (interest, motivation, confidence), but also induce the formation of critical thinking abilities by making the constructive comment in the class participation (June et al, 2014).

\subsection{Learning Autonomy}

ICT-based language learning has recently been focused by a great deal of researchers with an endeavor to promote EFL learning through the integration of ICT software and the traditional language teaching-learning. ICT integration principally can obsess in three different areas that is, curriculum, topic, and lesson. 
The increasing advancement of today's technology changed the way learners communicate as well as learn, hence they are supplied with technological knowledge in form of a global social network. As a result, they can be interconnected one other to interexchange, share, learn autonomously (Budianto, 2014). Moreover, he notes that technology, especially internet, presents new opportunity for authentic task and even authentic materials. And also, it offers the e-users to access a great deal of a wealth of ready-made ELT materials; a techno software-based medium serves online various types of information which can be accessed independently and autonomously. Consequently, the autonomy of language learning could be endeavored through giving the possibility of self-study. Therefore a self-study is easily undertaken through the use of technology software for promoting autonomous language learning and instruction (Budianto, 2014). Selfstudy leading to the autonomous leaning in EFL formal acquisition is significantly used to foster successful learning outcome, since EFL learners prefer choosing to study English with internet sources along with the autonomous EFL learning strategies. Thereby Budianto suggests the internet sources-based materials can be traced through learners who can independently work on behalf of their own needs, interest, and learning preferences.

The e-media must have been so motivating towards EFL learners, where those can pronely be accessed as supporting resources for learners with not only normality, but also disability or specific learning needs. Eventually, Learners can develop autonomously appropriate learning activities which base on process and even product, in which those can contribute to the authentic communication activities via group works, simulation, and authentic materials, then these activities may be beneficial to technology literacy skills. The concept of autonomous learning is a self-awareness, decision-making skills. It is an emphasis on learning freedom, in which an ability and willingness can make a choice and develop learning autonomy. Thereby an autonomy is the way language learner is able to work independently as well use the sustainable learning strategies in the classroom or even outside the classroom (Shariff \& Shah, 2019). Moreover, they reveal that the positive impact of videos having websites-based language learning contributes to authentic and autonomous learning environments. The advantages of e-media is much more accessibly utilized and always readily available. $\mathrm{Al}$ in $\mathrm{al}$, YouTube application is worthily 
recognized as means to trigger learners to control their learning pace and learning strategies.

The incorporation of EFL learners' experience related to software-based have noted that the blending strategies can manage and control their learning process, in order to enhance language learning outcomes. Thus these kinds of language learning can be categorized as a constructible way of learning by combining lives' experience with elearning bases. On the other hand, the practice of YouTube-based learning can encourage EFL learners' autonomy through a collaborative teaching and the understanding towards teachers' characteristics as collaborator to seemingly tend to use the certain methods. In relation with YouTube as language learning evoking self-autonomy and self-control, according to Chen (2013), this language learning practice is principally called as an experiential learning, where learners use their own power of observation and interpersonal skills so as to achieve learning outcomes through usefully and meaningfully learning to.

\subsection{Learning Interest}

Variety of language learning demands highlights the availability of the transformational learning methodologies in some fields especially in education. It is thought that a teacher has a role to design or to construct how to incorporate a new paradigm to the existing language learning problems. So, as the fact that those can be unraveled in purpose of constructing a new trend in EFL learning. With the increasing advancement of today's technological software, a need to embrace the virtual tools to boost English language teaching and the intent to make use technology tools in a language learning is empirically described by the practical experiences in EFL teaching and learning. As foreformulated by Levy (1997 in Barreto, 2018), on the concept of CALL (Computer-Assisted Language Learning) consisting of exploration and analysis of the application of computer in English language learning and teaching. The significant computer's application offers a wide range of uses for EFL learning and gives the opportunities to produce as well as present the significant contexts.

Mastery of a new technology necessarily contributes to increase EFL learners' interest through variety of new educational strategies. Moreover, technobased can lead two opportunities for teachers, namely both the opportunity to practice the pedagogical technological concept by using technological media, and the opportunity to design the language 
materials by adopting the use of technology-based language instruction.

It is urgent that EFL teachers must design English language learning method in purpose of presenting ease as new way to stimulate learners' interest. Thereby the emergence of leaners' interest can increase the efficacy of language mastery process through the practice of new technological techniques, YouTube. In short, the simulated intervention in EFL speaking skills development by using YouTube may motivate learners by modeling new YouTube video-based strategy which they can easily access, personally use, and even authentically do. Thus what is so-called as process above can properly be employed. The use of such technique is possible to facilitate leaners' outcomes (Alkathiri, 2019). Additionally, he concluded that YouTube has great potential to maximize confidence by minimizing learning anxiety and fears to exaggerate spoken language skills. The use of this model contributes towards both helping understanding lesson, and finding YouTube as a beneficial skill of language learning. Spoken skills of language learning process could be identified as a successful learning gain if EFL learners could seemingly acquire two levels of language mastery in both organization of ideas in speaking, fluency, and an ability of guessing new words' meaning. In other words, this can represent an engaging language learning method by stimulating EFL learners to socially participate in a meaningful engagement.

In line with the trend of webs-based today's EFL learning, it is criticized by Panagiotidis et al, (2018), that the availability of the integration of digital technology into EFL learning and instruction is not a novel innovation. The advancement of web 2.0 along with the digital means seemingly tend to have contributed as an accelerating effect to EFL learning process. This advancement is because of the digital natives, in which the digital natives are regarded as e-users having familiarity with any types of technology software, have been highlyskilled at multitasking in the modern information which can pronely be accessed. And also, they strongly tend to use technological means for facilitating themselves in effective learning. Furthermore, Panagiotidis et al (2018) add that the availability of the ubiquitous websbased learning media can impact on both how they intend to study as well as to be taught in any level of education, and learning and instruction which are used. Al in all, technology-based language learning can undoubtedly possess the positive impacts to stimulate learning interest or motivation and to lead the better learning 
achievement (Woodrow, 2017 in Panagiotidis et al, 2018), in not only the contexts of institutionalized education, but also the contexts of outside informal learning settings.

\section{CONCLUSION}

Web 2.0 software, YouTube, representing visual materials is needed to have represented the authentic subjectmatters and the visual aids to help EFL learners facilitate their own English learning. YouTube is one of media serving a great deal of English websites comprising of the plethora of online driven videos-based language learning sources. The effective characteristics of videoassisted e-media is worthily regarded as the significant paradigm to transform the traditional one from teacher's centeredness to student's centeredness. Thus novel model of language instruction-learning could have been considered to have contributed to facilitate EFL learners' language social engagement process. The effectiveness of YouTube in promoting English proficiency is significantly affected by the authenticity of learning materials, easily accessed resources, and attractive language learning e-media. Therefore, the use of YouTube medium in purpose of developing English proficiency can produce the development of critical thinking skills, independency of language learning with more autonomy, and learning interest building.

\section{REFERENCES}

Alkathiri, L.A. (2019). Students'

Perspectives towards Using Youtube in Improving EFL Learners' Motivation to Speak. Journal of Education and Culture Studies. 3 (1): 12-30

Almurashi, W.A. (2016). The Effective Use of Youtube Videos for Teaching English Language in Classrooms as Supplementary Material at Taibah University in Alula. International Journal of English Language and Linguistics Research. 4 (3): 32-47

Bajrami, L. and Ismaili, M. (2016). The Role of Video Materials in EFL Classrooms. Procedia-Social and Behavioral Sciences. 232, 502506

Barreto, A.M.R. (2018). Motivating English Language Use by Using the Benefits of Technology. Gist Education and Learning Research Journal. (16), 117-140

Brooks, A. (2004). Posfeminisme \& Cultural Studies: Sebuah Pengantar Paling Komprehensif (S. Kunto Adi Wibowo, penerjemah dan Idi Subandy Ibrahim, editor). Yogyakarta: Jalasutra. (Karya asli diterbitkan pada 1997).

Bastos, A. and Ramos, A. (2009) Youtube for Learning English as a Foreign 
Language: Critical Thinking, Communicative Skills. Proceedings of EDULEARN09 Conference, Barcelona, Spain.

Budianto, L. (2014). Promoting Students' Autonomous Learning through ICT Based Learning in ICP: A Case Study. LiNGUA. 9 (2), 125134

Brunner, I. (2013). Using Language Learning Resources on Youtube. International Conference "ICT for Language Learning" $6^{\text {th }}$ edition. 1-5

Brook, J. (2011). The Affordance of YouTube for Language Learning and teaching. Hawaii Pacific University TESOL Working Paper Series 9.1 (2), 37-56

Chen, Y. (2013). The Possibility of Applying YouTube to Motivate Learning Autonomy. Journal of International Education

Research. 9 (3), 207-216

Dodd, R et al., (2015). The Use of Supplementary Materials in English Foreign Language Classes in Ecuadorian Secondary Schools. English Language Teaching. 8 (9), 187-195

Duffy, P. (2008). Engaging the YouTube Google-Eyed Generation; Strategies for Using Web 2.0 in Teaching and Learning. The Electronic Journal of e-Learning. 6 (2), 119-130
Ismaili, M. (2013). The Effectiveness of Using Movies in the EFL Classroom- A Case Study Conducted at South East European University. Academic Journal of Interdisciplinary Studies. 2 (4), 121-132

Jalaluddin, M. (2016). Using YouTube to Enhance Speaking Skills in ESL Classroom. English for Specific Purposes World.17 (50), 1-4

June et al., (2014). Assessing the Use of YouTube Videos and Interactive Activities as a Critical Thinking Simulation for Tertiary Students: An Action Research. International Education Studies. 7 (8), 56-67

Kawamura, M. and Wu, P.H.N. (2015). Developing Critical Thinking Skills through Content Base Learning Using Media. International Conference on Communication, Health, Beauty, and Innovation Education (CHBIE).

Kelsen, B. (2009). Teaching EFL to the iGeneration: A Survey of Using YouTube as Supplementary Material with College EFL Students in Taiwan. CALL-EJ: Conference Presentation on $2^{\text {nd }}$ Conference on College English, National Chengchi University, Taipei, Taiwan. 1-20

Konoplianyk, L. (2018). Use of Authentic Video Materials in Teaching ESP for Future Civil Engineers. 
Volume 3 No. 2, August 2020

Candidate of Pedagogical

Sciences. 464-480

Mohammadi, N. et al., (2011). Effects of eLearning on Language Learning. Procedia Computer Science. 3, 464-468

Noordin et al.,(2014). Integrating Communicative Approach and Technology in ESL Classroom. Journal of Business and Social Development. 2 (1), 30-36

Panagiotidis et al., (2018). Technology as a Motivational factor in Foreign Language Learning. European Journal of Education. 1 (3), 4352
Soliman, N.A. (2019). Using E-Learning to Develop EFL Students' Language Skills and Activate Their Independent Learning. Creative Education. 5, 752-757

Syarif, S.B.M. and Shah, P.M. (2019). Pupils Perception of Using YouTube and Autonomous Learning. Creative Education. 10, 3509-3520. https:doiorg/10.4236/ce.2019.10/3270

Watkins, J. and Wilkins, M. (2011). Using Youtube in the EFL Classroom. Language Education in Asia. 2 (1), 113-119 
Volume 3 No. 2, August 2020

P-ISSN 2623-0062

Universitas Banten Jaya

E-ISSN 2622-9056 
Volume 3 No. 2, August 2020

P-ISSN 2623-0062

Universitas Banten Jaya

E-ISSN 2622-9056 
Volume 3 No. 2, August 2020

P-ISSN 2623-0062

Universitas Banten Jaya

E-ISSN 2622-9056 